\title{
Trends in electricity prices and their relation to the competitiveness and efficiency in $\mathrm{EU}$ countries
}

\author{
A. Martínez, S. Valero, E. Velasco and C. Senabre \\ Electrical Engineering Area \\ Universidad Miguel Hernández de Elche \\ Avd. de la Universidad s/n. Edificio Quorum-V, 03202 Elche (Spain) \\ Phone: 0034966658969 / 616201717, e-mail: alberto.martinez@umh.es, svalero@umh.es
}

\begin{abstract}
Europe is emerging from a deep financial and economic crisis and it is widely agreed that stronger European industrial competitiveness is vital as a driver for economic growth and job creation. In this regard, while ensuring the achievement of essential climate and environmental objectives, it is now recognised that it is imperative to ensure that EU energy Union is shaped in such a way to guarantee, not only security of supply for all consumers, but also stable and affordable energy prices for European businesses.

This article offers the opportunity to analyse, all the crucial and sensitive components of the prices of energy in some UE countries: economic, financial and technological conditions required to develop renewable energy and other domestic energy resources in order to reduce European dependence on thirdcountry suppliers; development of infrastructure and internal as well as cross-border interconnections; overhaul of national practices on energy levies, tax components of energy prices and network costs; moderation of energy demand and increase of energy efficiency.
\end{abstract}

\section{Key words}

Energy, prices, electricity, efficiency, competitiveness.

\section{Introduction}

The developments in the EU28 power sector have significant impacts on energy costs and electricity prices, in particular in the short term. Power generation costs significantly increase, mainly as a consequence of higher investments due to the need for significant capital replacement and higher fuel costs (because of the large increase in international fossil fuel prices). Grid costs also increase to recover high investment costs in grid reinforcements and interconnectors, which are fully consistent with the provisions of the RES 2020 target. Smaller components of the cost increase are national taxes and ETS allowance expenditures. In addition, there are the arithmetic effects of successful energy efficiency policies, which through curtailing electricity demand reduce the denominator for sharing out the electricity costs while the numerator is less affected due to the high share of fixed costs in electricity generation and supply. As a result, average electricity price in the period 2010-20 increases by $31 \%$. [1]

The infrastructure of electricity is oversized in some countries because of the predicted fatal errors and the economic crisis. This has given rise to an immense power generation infrastructure that has resulted in an overcapacity to satisfy the demand for electricity; this then exacerbates the tension and volatility of energy and electricity prices in particular. [3]

Factors such as the degree of self-sufficiency, distribution of the GDP per sectors, the share of nuclear power and the development of renewable energy, has a significant influence that is significant when studying the behaviour of the final prices in European countries.

\section{Prices analysis}

It appears that market liberalization has worked to put downward pressure on prices in market segments where liberalization was allowed, (wholesale markets). In retail, market opening is still held back by the end-price regulation. Furthermore, any liberalization effect on the energy component in end consumer bills is curtailed in most Member States by a strong rise of taxes on selected energy products. [4]

In contrast with retail, the wholesale electricity prices moved much in line with the prices of crude oil and natural gas. This development suggests that margins were gradually reduced along the supply chain, especially for vertically integrated companies. Even in a fully unbundled situation this development may have negative impacts on investment decisions in the upstream (generation) or passing-over effects to the downstream (sales companies). 
In Figure 1 the distribution of costs for domestic consumers in three areas of activity in the electricity market is shown: firstly the costs arising from supply and generation of electricity, secondly the cost of transport and distribution and finally the costs associated with taxes and fees applied. It can be seen that in those peripheral or island countries, the costs of power generation are more important, as in Spain, UK and Italy. The costs related to transmission and distribution, are significantly important in the Central European countries. Regarding to Germany the high taxes is noteworthy that mean almost $50 \%$ of the costs. Finally, it should be highlighted the low taxes paid by domestic consumers in the UK.

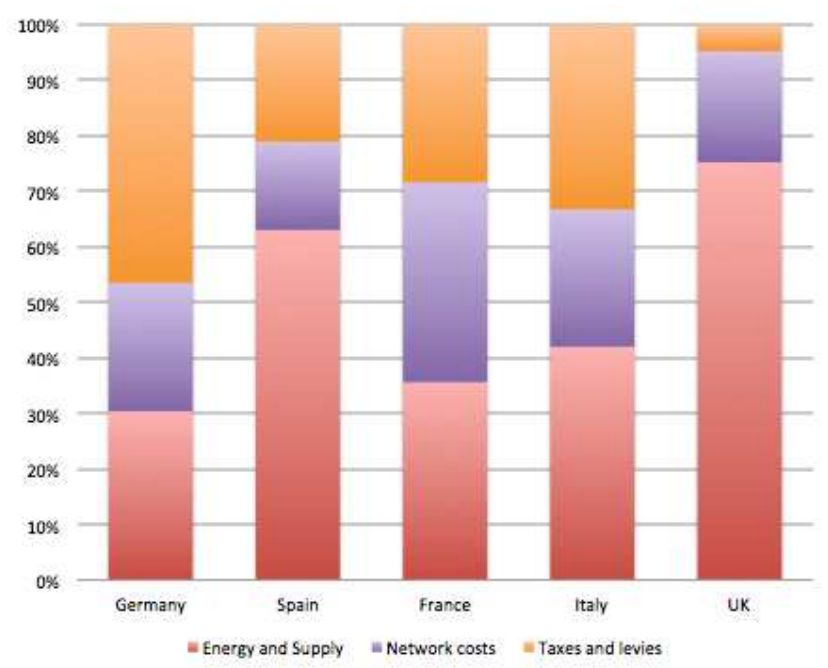

Fig. 1. Electricity prices for domestic consumers in 2013 Breakdown by: Energy, Network (transmission+distribution) and Taxes (VAT and other) Source: Eurostat [2]

It is interesting to compare this situation with the profile of industrial consumers, in which the characteristics of distribution costs vary significantly, as shown in Figure 2.

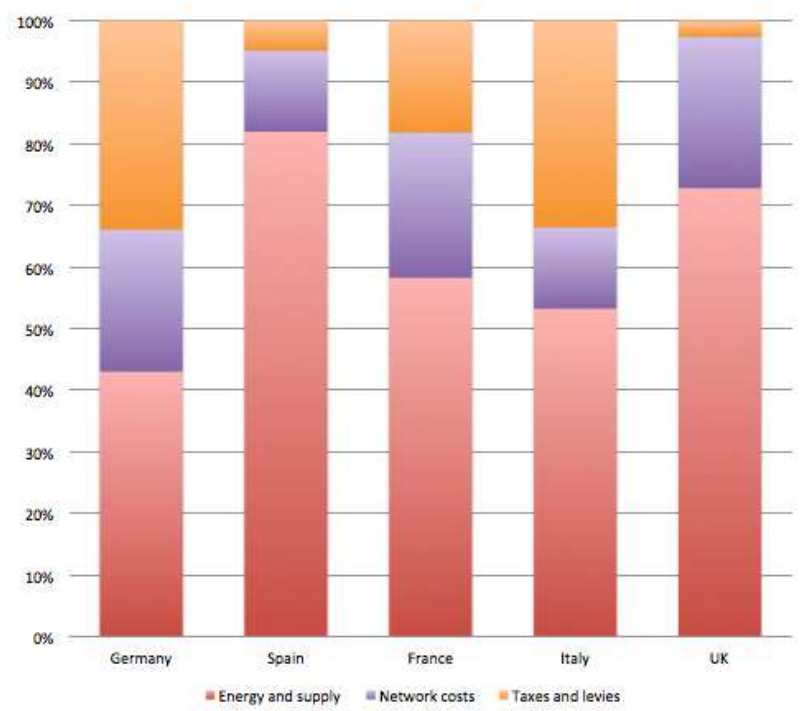

Fig. 2. Electricity prices for industrial consumers in 2013 Breakdown by: Energy, Network (transmission+distribution) and Taxes (VAT and other) Source: Eurostat [2]
You can see major differences in distribution of prices between Figure 1 and Figure 2. Figure 2 is to highlight the efforts of governments in general to minimize the tax, like in Spain, in order to penalize the least cost electricity in the industrial sector and to promote the maintenance of high productivity ratios. Overall tax bands and network costs are reduced, leaving more value to the cost of power generation.

But at this point, an important question arises, how to determine the characterization of electrical supplies?. According to the latest monthly newsletter of electrical and economic indicators in Spain [5], the structure of the national consumer access rate indicates that $99.62 \%$ of consumers buy the electricity at low voltage, and they consume the $49 \%$ of total electricity in the country. The rest of the supplies $(0.38 \%)$ acquire the $51 \%$ of the energy. These data raise serious doubts about the bargaining power of 27.6 million of customers which is sprayed almost half the country's energy consumption, and the other half is consumed by just over than 0.1 million users.

But this analysis would be incomplete if we did not analyze the evolution of prices in absolute terms.

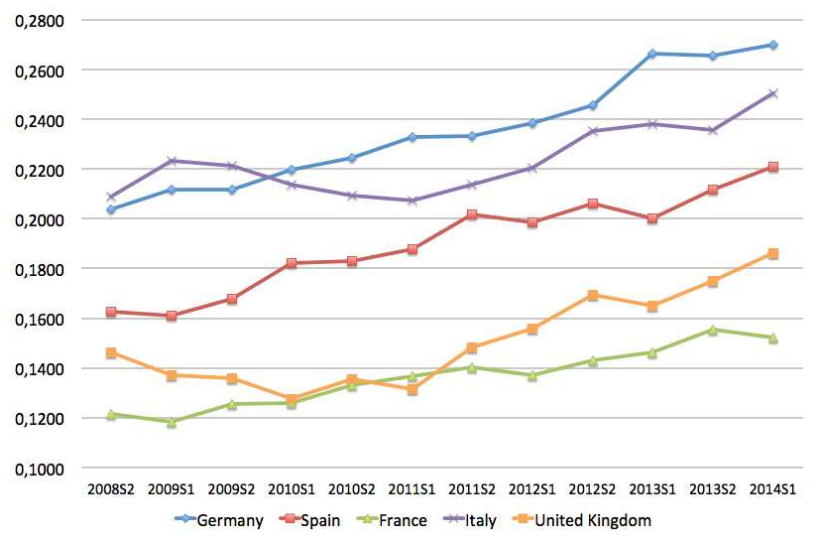

Fig. 3. Price of electricity - Domestic Consumers (including Network Costs and Taxes. Exc. VAT) (€/kWh) Source:

Eurostat [2]

As shown in Figure 3, the energy prices for the domestic consumer of the main European countries with similar (no geopolitical) demographic growth is mainly clear for the reasons stated in the introduction to this article.

At the industry level, prices follow a similar upward trend, although with a little bit less growth, as shown in Figure 4.

The highest electricity prices in Italy have to be highlighted, that are more expensive than Germany that, as it is well known, the country has the higher tax on energy costs. 


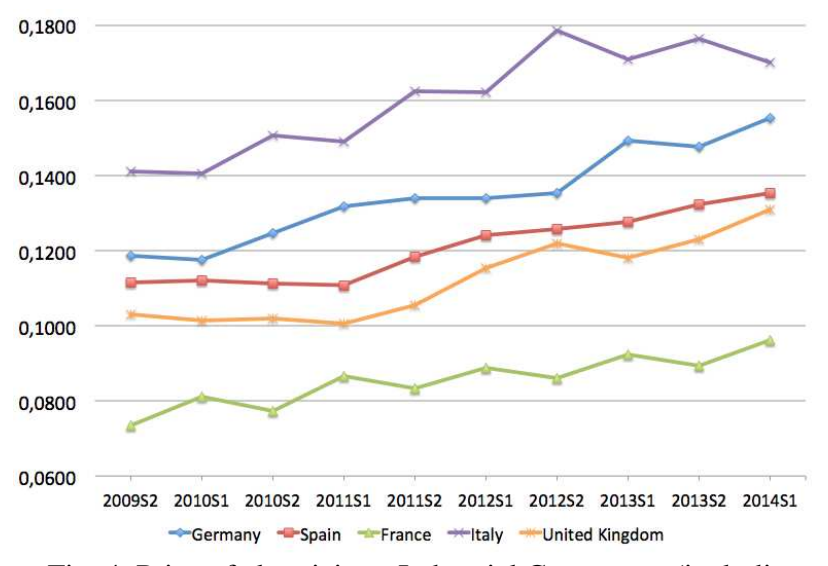

Fig. 4. Price of electricity - Industrial Consumers (including Network costs and Taxes. Excluded VAT) (€/kWh) Source: Eurostat [2]

\section{The efficiency problem}

National taxation policies exert a lasting impact on end consumer prices. Fiscal policies of Member States differ in the extent and the objectives of taxes applied to final electricity and gas prices. The relative share of the taxes for the group of EU 15 varies from 5\% (UK) to more than $50 \%$ (DK); tax revenues could be earmarked for a particular support scheme for a generation technology or they could represent an important source of revenue for the national budget. It seems that the share of taxes is gradually increasing. For EU15 it represented $28 \%$ of the final price for domestic consumers in 2010, against $22 \%$ in 1998. The corresponding figures for industrial users were $19 \%$ in 1998 against $27 \%$ in 2010. [3]

Efforts from states to achieve the increase of competitiveness are important, but unfortunately not all of them are reaching it. According to Eurostat data [1] it can be shown that Spain was in the line of efficiency with a positive economy in general and also in all the countries considered, but in 2012 there was a significant change in trend probably linked to policies and regulatory changes mainly applied in employment (Figure 5).

In August 2011 the new Law 27/2011 was approved about updating, improvement and modernization of the social security system in Spain. Subsequently, in July 2012, the Law 3/2012 was approved about urgent measures to reform the labor market. You can see in Figure 5 the effect of these policies and the increase on labor productivity. However, the improvement in the energy intensity in the economy of Spain is negligible, far from the positive performance of other countries. This may be due to the reduction of energy consumption in the country in the year 2012 said by the Ministry of Industry and Energy [6] Primary energy consumption in Spain in 2011 marked a negative trend of $-0.6 \%$ together with the decline in 2012 of a $-0.4 \%$ and due to a very slow rise in GDP [2]. The energy intensity in the economy in 2012 is almost equal to 2010 in Spain, far from the improvements in other countries.
For the study we have chosen the approach of using the ratio of the energy intensity in the economy considering the consumption of primary energy, and this energy is obtained as a result of adding the consumption of final energy consumption in the energy sectors (own consumption and changing consumption, especially in power generation and oil refineries) and losses, allowing us to include the concept of efficiency in energy infrastructure of the country.

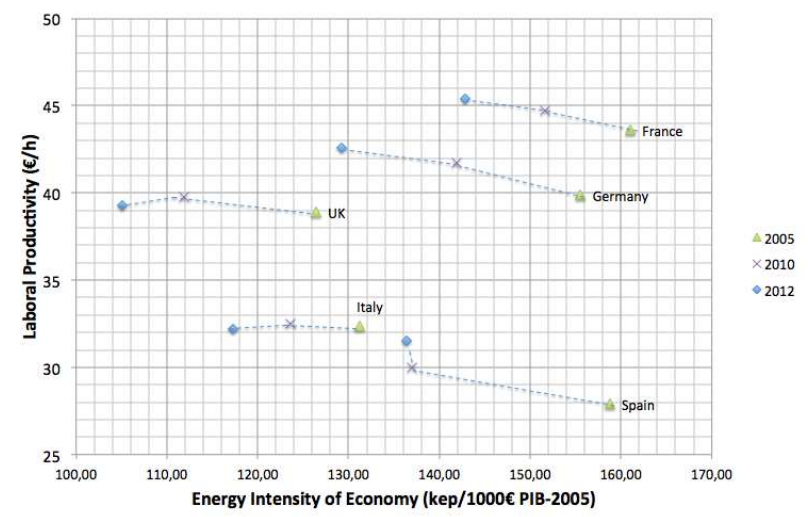

Fig. 5. Laboral Productivity ( $€ / \mathrm{h})$ in comparison with Energy Intensity of Economy (kgoe/1000€) Source: Eurostat [2]

It does not help at all the increase of energy prices and their impact on citizens. As shown in Figure 6, the situation in Spain in 2012, there was a significant deviation, as compared to other countries in the study, in which energy prices for domestic consumers increases highly, far away from the normal evolution of others countries studied. See the so different trend with polynomial regression coefficients of $\mathrm{R}^{2}=0.99678$ in 2010 and $R^{2}=0.41273$ in 2012 , mainly because Spain.

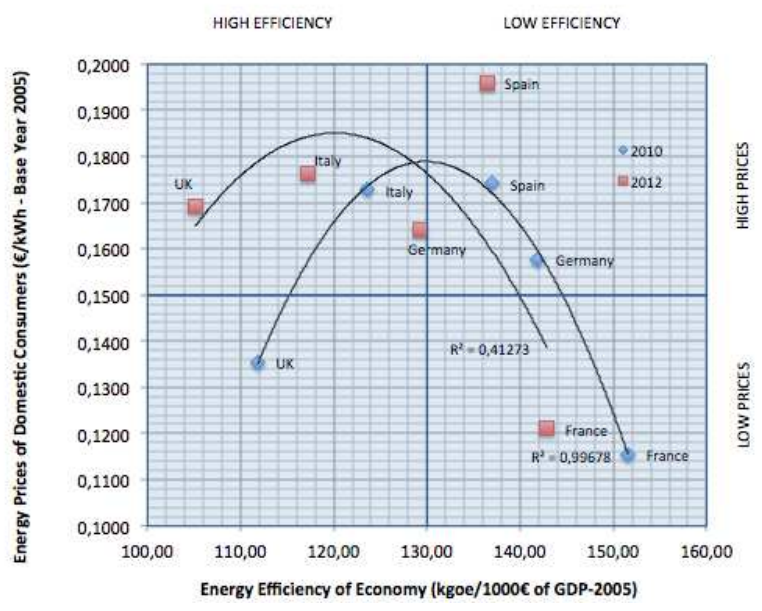

Fig. 6. Comparison between Energy Prices of Domestic Consumers (excluded taxes, levies and VAT) (€/kWh) and Energy Intensity of Economy (kgoe/1000 €) Source: Eurostat [2] 


\section{Competitiveness of economies}

Prices studied in the previous section offers objective information on prices that the consumer has to pay for electricity. But those prices considered in isolation have to be adapted to the economic situation of the country which means also to consider, the user's financial capacity to afford its spending on power (from the standpoint of the domestic user) and (from the point of view of the industrial user) the level of competitiveness for business from the energy point of view.

From a domestic point of view, we will relate the income per capita to the level of electricity prices in the domestic consumer, as shown in Figure 7. In addition, for the analysis the "time" variable will be introduced by comparing the situations in the last five years.

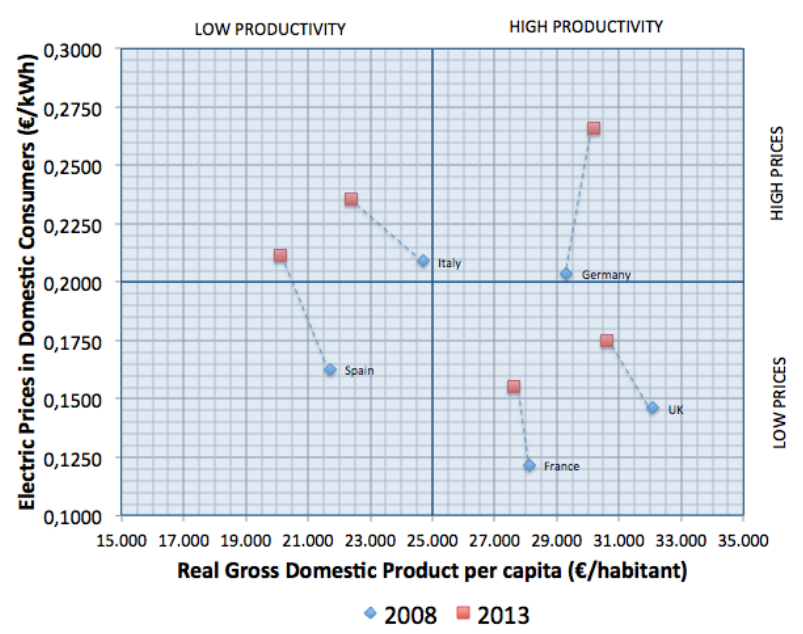

Fig. 7. Comparison between Electric Prices in Domestic Consumers ( $€ / \mathrm{kWh})$ and GDP per capita ( $€ /$ habitant) Source: Eurostat [2]

Comparing the price situation in the member states analyzed, it can be observed, in general, that the income per capita is declining, except in Germany that is the only country with its income per capita growing.

Related to Italy and Spain, they have the higher decrease, but Spain is suffering the worst situation: lower disposable income for citizens and an important increase of electricity prices in the domestic sector. Italy and Spain are under low productivity and high energy prices, so there is great risk of raising the threshold of energy poverty of citizens.

On the other hand, from the industrial point of view, we analyze the situation of the countries comparing the industrial added value. As shown in Figure 8, the situation in France, UK and Italy is similar. The evolution of prices is upward and the contribution of the industrial sector that remains at the same level. Spain is one of the lasts when the value added is compared for industrial sector. Germany has the double values of industrial activity, and also, in the last five years, had a growth of almost $25 \%$ in its activity. But prices of electricity in the industrial sector have also experienced a high growth.

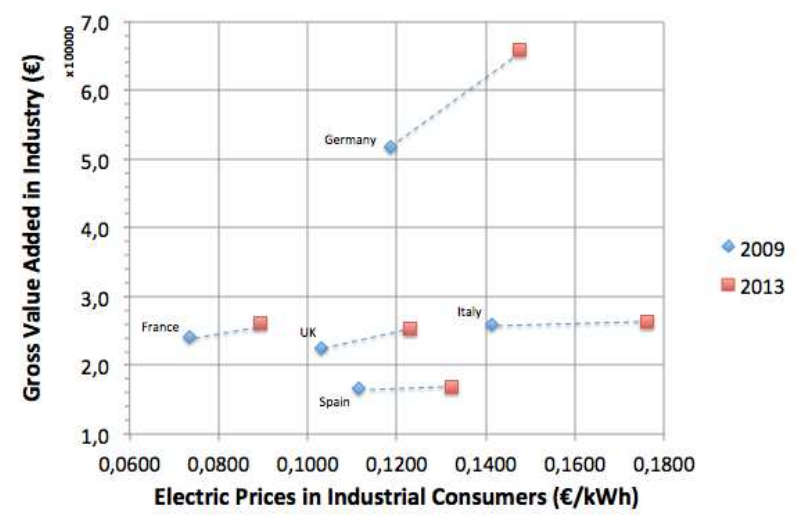

Fig. 8. Gross Value Added in Industry $(€)$ in comparison with Electric prices in industrial consumers (excl. VAT) $(€ / \mathrm{kWh})$ Source: Eurostat [2]

Finally, analyzing prices in the industrial sector of the countries studied (Figure 9), but excluding costs of taxes and VAT, it can be seen that countries such as Spain, Italy and the UK, have the highest prices. In Italy there has been an important decrease since 2012. Interestingly, the decrease of prices in Germany and Italy since 2012, contrasts to the general increase in all countries considering taxes (Figure 4), so we can conclude Member States increase the taxes when possible price reductions may occur in the prices of electricity.

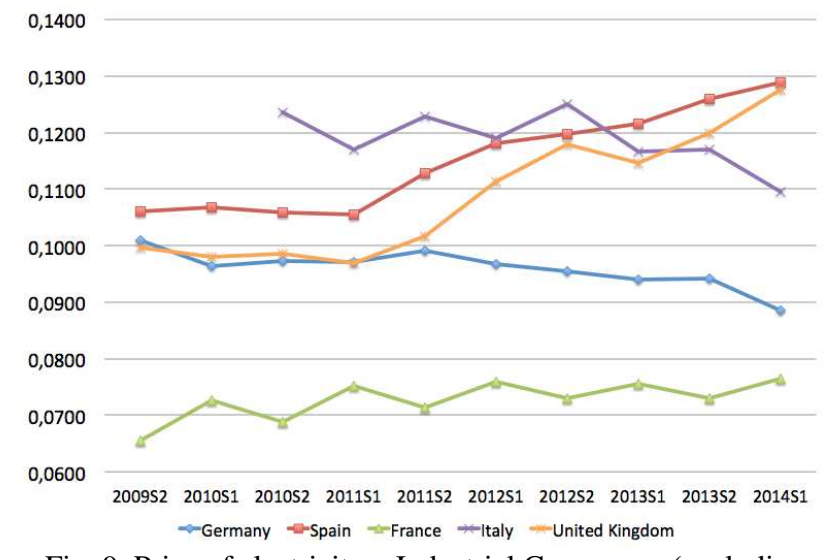

Fig. 9. Price of electricity - Industrial Consumers (excluding Taxes, levies and VAT) (€/kWh) Source: Eurostat [2]

It is interesting to highlight the reduction of the Index of Industrial Production in Spain comparing prices in each sector as an indicator of the industrial competitiveness of the country (Figure 10). The Industrial Production Index is an indicator that measures the evolution of industrial economic activity excluding construction. It is significant that the evolution of industrial activity is inversely proportional to the electric price level in industrial consumer in Spain. 


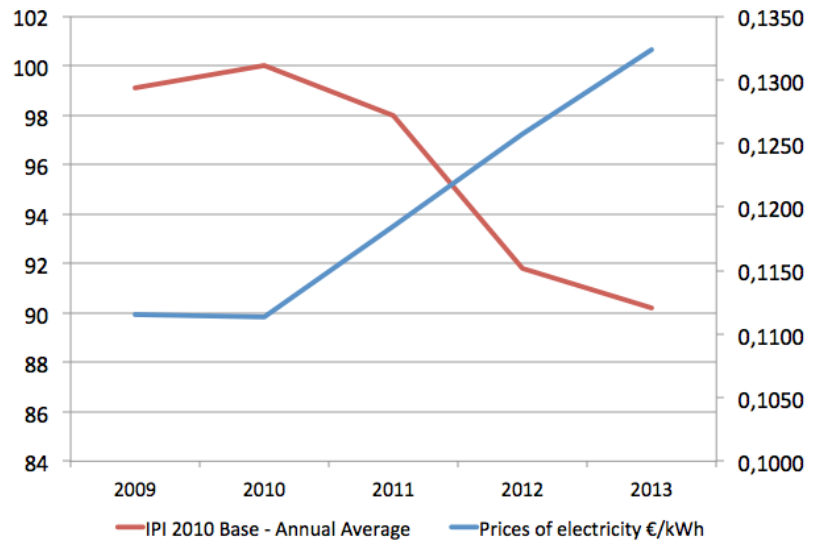

Fig. 10. Prices of electricity in Industrial Consumer ( $€ / \mathrm{kWh})$ in comparison with Industrial Productivity Index in Spain. Source: Eurostat [2] and INE [7]

\section{Conclusion}

In this article the prices of electricity, its composition and linkage to competitiveness and productivity of a country have been analyzed.

As a first conclusion, taxes on electricity are not the same in all countries, and have no relation with competitiveness. For instance, Germany, with high industrial ratios of productivity in the Eurozone, also suffers higher taxes on their electric bill. On the other extreme there are the countries of the Mediterranean area, such as Italy and Spain, with lower rates of productivity and with different scenarios, Italy is heavily penalized in their taxes, meanwhile Spain has the lowest tax rates, after Britain. In the case of Italy, it would mean an increase for their competitiveness reducing tax on their electric power. In the case of Spain, improving industrial productivity it would be found other no energy variables. Spain also has the most expensive level in the domestic electricity consumption, before taxes and fees (Figure 6) and this situation is still maintained in year 2014. Therefore, the reduction of domestic consumption through energy efficiency, finding alternative domestic consumption profile and policies that encourage and promote different patterns in these two fields, decrease consumption and therefore, will produce a price reduction, according to free market rules.

Regarding to the energy bill; we can conclude that Spain, with a very low income per capita, is a country with very high-energy prices for the householders. Therefore, Spanish citizens have higher risks of raising the energy poverty threshold.

It can also be concluded that Spanish industrial competitiveness is one of the lowest of the countries studied. This article does not the reasons for the lack of competitiveness of Spain, but it has to been highlighted the high level of Spanish energy prices (before taxes, fees and VAT) compared with the other countries studied.
Finally, It has been studied some countries that have reduced the price of energy (before tax, levies and VAT), results that their governments have increased the taxes on electricity. Therefore, a general rise in prices across the all countries can be observed.

\section{References}

[1] EU Energy, Transport and GHG Emissions. Trends to 2050. Reference Scenario 2013 - Publications Office of the European Union - 2014 - ISBN 978-92-79-33728-4

[2] EUROSTAT [on-line] - European Commission Statistics Database - [consulted 2014]. Available at: http://epp.eurostat.ec.europa.eu/portal/page/portal/eurostat/hom el

[3] A. Martinez, S. Valero, E. Velasco, "Energy intensity of the economy as a variable to measure the energy efficiency of a country: comparison between European member states" Renewable Energy and Power Quality Journal (RE\&PQJ) ISSN 2172-038X, no 12, Abril 2014

[4] Price developments on the EU retail markets for electricity and gas 1998 - 2011 [on line] - Market observatory \& Statistics - European Commission [consulted 2014]

[5] CNE [on line] Comisión Nacional de Enegía - Boletín Mensual de Indicadores eléctricos y económicos - Septiembre 2013

[6] Libro de la Energía en España 2012 [on line] - Ministerio de Industria y Energía. Secretaría de Estado de Energía, Centro de Publicaciones de la Subdirección General de desarrollo normativo, informes y publicaciones. [consulted 2014] http://www.minetur.gob.es

[7] Anuario estadístico de España 2014 [on line] - INE [consulted 2014] http://www.ine.es 